Article

\title{
Effects of Urban Expansion on Forest Loss and Fragmentation in Six Megaregions, China
}

\author{
Weiqi Zhou ${ }^{1,2, *}$, Sai Zhang ${ }^{1,2}$, Wenjuan Yu ${ }^{1}$, Jing Wang ${ }^{1,2}$ and Weimin Wang ${ }^{3}$ \\ 1 State Key Laboratory of Urban and Regional Ecology, Research Center for Eco-Environmental Sciences, \\ Chinese Academy of Sciences, Beijing 100085, China; zhangsai15@mails.ucas.edu.cn (S.Z.); \\ wjyu@rcees.ac.cn (W.Y.); wangxiaojing.1126@163.com (J.W.) \\ 2 University of Chinese Academy of Sciences, Beijing 100049, China \\ 3 Shenzhen Environmental Monitoring Center, No. 8, RD. Meiaoqi, Shangmeilin, Shenzhen 518049, China; \\ towmwang@163.com \\ * Correspondence: wzhou@rcees.ac.cn; Tel.: +86-10-6284-9268; Fax: +86-10-6291-5372
}

Received: 30 July 2017; Accepted: 22 September 2017; Published: 26 September 2017

\begin{abstract}
Urban expansion has significant effects on forest loss and fragmentation. Previous studies mostly focused on how the amount of developed land affected forest loss and fragmentation, but neglected the impacts of its spatial pattern. This paper examines the effects of both the amount and spatial pattern of urban expansion on forest loss and fragmentation. We conducted a comparison study in the six largest urban megaregions in China-Beijing-Tianjin-Hebei (BTH), Yangtze River Delta (YRD), Pearl River Delta (PRD), Wuhan (WH), Chengdu-Chongqing (CY), and Changsha-Zhuzhou-Xiangtan (CZT) urban megaregions. We first quantified both the magnitude and speed of urban expansion, and forest loss and fragmentation from 2000 to 2010. We then examined the relationships between urban expansion and forest loss and fragmentation by Pearson correlation and partial correlation analysis using the prefecture city as the analytical unit. We found: (1) urban expansion was a major driver of forest loss in the CZT, PRD, and CY megaregions, with $34.05 \%$, $22.58 \%$, and $19.65 \%$ of newly-developed land converted from forests. (2) Both the proportional cover of developed land and its spatial pattern (e.g., patch density) had significant impacts on forest fragmentation at the city level. (3) Proportional cover of developed land was the major factor for forest fragmentation at the city level for the PRD and YRD megaregions, but the impact of the spatial pattern of developed land was more important for the BTH and WH megaregions.
\end{abstract}

Keywords: urban growth; urbanization; land cover change; urban agglomeration; remote sensing; patch density; landscape change; urban ecology

\section{Introduction}

Urbanization has long been considered as a major force of land use/land cover (LULC) change worldwide, which is associated with changes in local and regional climate, environments, and natural resources [1-4]. In fact, urban expansion has been seen as a major threat to loss and fragmentation of natural landscapes, and a major driver of numerous environmental and ecological problems [5-9]. For example, loss and fragmentation of forests caused by urban expansion has raised great attention worldwide [10-12]. This is because forest loss and fragmentation have adverse impacts on a variety of ecological process and functions, such as deterioration of wildlife habitat quality [13] and threating biodiversity [14-16]. Understanding such impacts requires the quantification of forest loss and fragmentation associated with urban expansion $[10,17,18]$.

Remote sensing has long been used to quantify changes in forested land [17-20], as it can explicitly reveal its change in space in a recurrent and consistent way [21]. Changes in spatial pattern of forested land have been typically studied by combining remote sensing data with landscape metrics [22]. 
Remote sensing imagery with different spatial resolution was used, ranging from Advanced Very High Resolution Radiometer (AVHRR) data with $8 \mathrm{~km}$ resolution, to medium-resolution imagery, such as $250 \mathrm{~m} / 1 \mathrm{~km}$ Moderate Resolution Imaging Spectroradiometer (MODIS) and $30 \mathrm{~m}$ Landsat TM imagery, and high-resolution imagery, such as $1 \mathrm{~m}$ IKONOS imagery.

Previous studies on the effects of urban expansion on forest loss and fragmentation can be loosely categorized into three types. The first type of studies focuses on urban expansion and associated land use change, with emphasis on forest loss in the urban-rural periphery, e.g., [23-25]. The second type of studies focuses on the spatiotemporal pattern of urban expansion along an urban-rural gradient and how such patterns affect the changes (both gain and loss) in forested land, e.g., [10,26-28]. The third type of studies explicitly addresses the spatial patterns of forested land and its change associated with urbanization, $[17,18,29,30]$. In addition to change in the area of forested land, these studies focus on the spatial distribution of forests, with particular emphasis on forest fragmentation caused by urban expansion. Most of these studies have focused on the adverse impact of the increased urban land on forest loss and fragmentation.

Few studies, however, have examined how the spatial distribution of the developed land affected forest loss and fragmentation. For example, research questions such as "In addition to the increase of the amount of developed land, does the spatial pattern (e.g., clustered versus dispersed) of newly developed land affect forest fragmentation?" Addressing such questions can provide important insights on understanding how urban expansion affects forest loss and fragmentation and, therefore, is important for smart urban growth and planning. This study aims to fill this gap.

The overarching goal of this study is to investigate the effects of urban expansion and its spatial patterns on forest loss and fragmentation. We conducted a comparative study in the six largest urban megaregions in China-the Beijing-Tianjin-Hebei (BTH), Yangtze River Delta (YRD) and Pearl River Delta (PRD), the Wuhan (WH), Chengdu-Chongqing (CY) and Changsha-Zhuzhou-Xiangtan (CZT) urban megaregions. Specifically, the objectives are to: (1) quantify urban expansion and its spatial pattern and forest loss and fragmentation from 2000 to 2010 in the six rapidly-urbanizing megaregions; and (2) examine the effects of urban expansion and its spatial pattern on forest loss and fragmentation from 2000 to 2010. Results from this study can provide insights on protecting forested land and reducing fragmentation during urban expansion processes.

\section{Materials and Methods}

\subsection{Study Area}

This study focused on six rapidly urbanizing megaregions in China, including the Beijing-Tianjin-Hebei (BTH), Yangtze River Delta (YRD), Pearl River Delta (PRD), Wuhan (WH), Changsha-Zhuzhou-Xiangtan (CZT), and Chengdu-Chongqing (CY) urban megaregions. The BTH, YRD, and PRD urban megaregions are distributed from the north to south of the eastern coastal region and are the three largest megaregions with relatively long development histories (Figure 1). The BTH urban megaregion includes two municipalities directly under the Central Government, Beijing and Tianjin, and Hebei Province. The YRD urban megaregion consists of Shanghai, eight prefecture cities in the south of Jiangsu Province, and six prefecture cities in the north of Zhejiang Province. The PRD megaregion includes nine cities in Guangzhou Province (Table 1). The total areas of the three megaregions are approximately $215,800 \mathrm{~km}^{2}, 103,960 \mathrm{~km}^{2}$, and $54,000 \mathrm{~km}^{2}$, with a total population of 111 million (8.07\% of the total population of China), 98 million (7.13\%), and 59 million (4.3\%) in 2015, respectively. The three megaregions are considered as the economic growth engine in China, with a total gross domestic product (GDP) of 21,456 billion Yuan, accounting for $31.3 \%$ of total GDP of China in 2015 [31-34].

The Wuhan (WH) and Changsha-Zhuzhou-Xiangtan (CZT) urban megaregions are located in the center of China, having sizes of $58,000 \mathrm{~km}^{2}$ and $27,980 \mathrm{~km}^{2}$, respectively (Figure 1). The WH megaregion includes eight cities of Hubei Province, and the CZT megaregion includes the city of 
Changsha, Zhuzhou, and Xiangtan in Hunan Province (Table 1). Both WH and CZT megaregions are the regions with the most potential for economic growth in Central China. In 2010, the GDP of CZT was 112.43 billion Yuan, which is quadruple the GDP in 2000. Although the size of the WH megaregion is less than one-third of entire Hubei Province, it had more than half of the total population in Hubei Province, and contributed to more than 60\% GDP in 2010 [35].

The Chengdu-Chongqing (CY) urban megaregion is located in the upstream of Yangtze River Basin, belonging to the western part of China (Figure 1). It consists of 15 cities in Sichuan Province and 22 counties in the municipality of Chongqing, with nearly 185,000 km² (Table 1). This megaregion is the most developed area in the Western China, with the total GDP of 3713 billion Yuan in 2014, accounting for $5.9 \%$ of the total GDP in China [36,37].

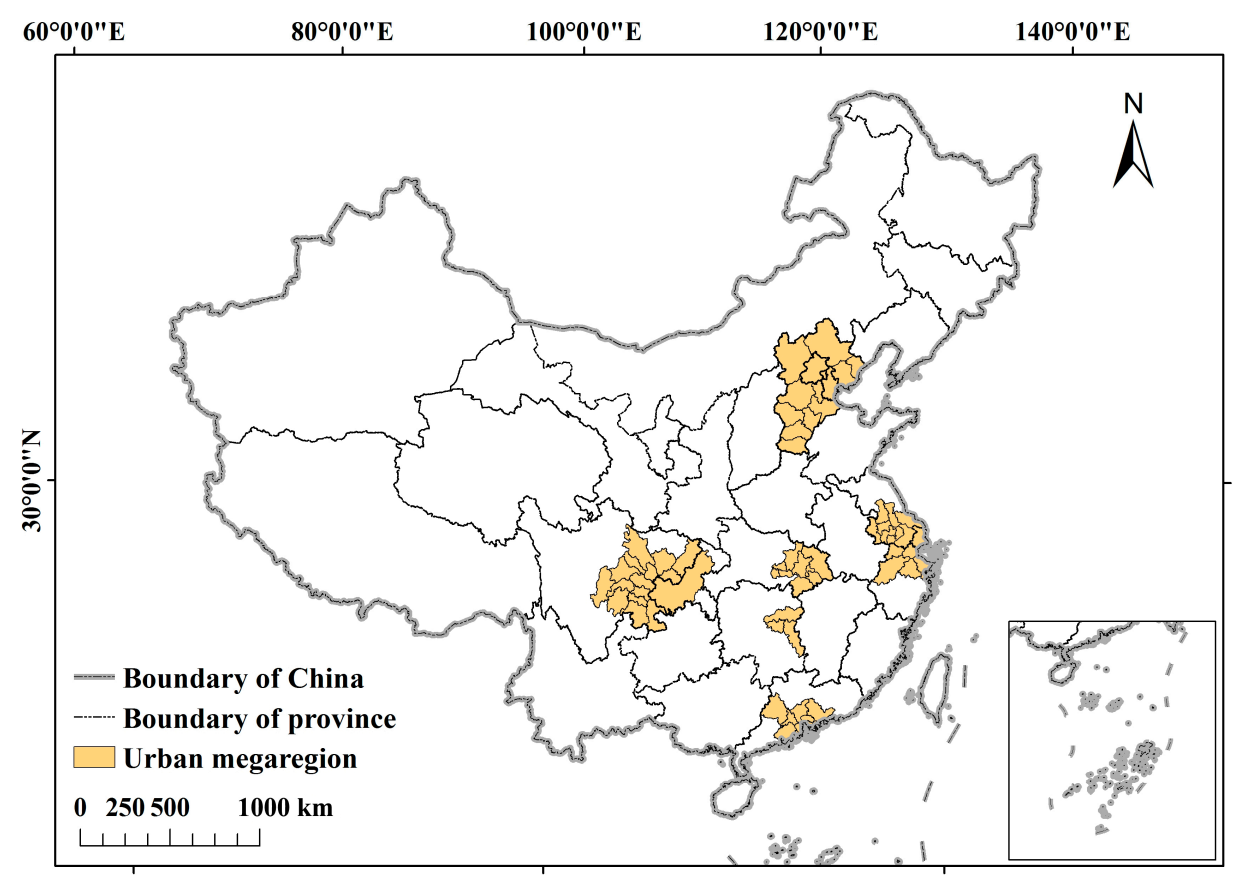

Figure 1. The spatial distribution of the six urban megaregions.

\subsection{Data}

Land use and land cover (LULC) classification maps of 2000 and 2010 were derived from Landsat TM/ETM+ imagery with $30 \mathrm{~m}$ spatial resolution. The Landsat TM/ETM+ images were obtained from the United States Geological Survey (USGS) archives. The primary processes have been performed for all the images through Level 1 Product Generation System (LPGS). Six types were included in the LULC classification maps: forest, grass, water, farmland, developed land and barren land (Figure 2). The forest type includes evergreen broadleaf forests, deciduous broadleaf forests, evergreen coniferous forests, deciduous coniferous forests, conifer, and broadleaf mixed forest and shrubs. Both natural forests and urban forests were classified as the type of forest. The grass type includes prairies, meadows, grasslands, tussocks, and urban lawns. Water includes lakes, reservoirs, rivers, and canals. Farmland consists of paddy land and dry land. Developed land includes urban and rural residential, commercial, institutional, industrial, and transport lands. Barren land includes bare soil, bare rock, and sand. 


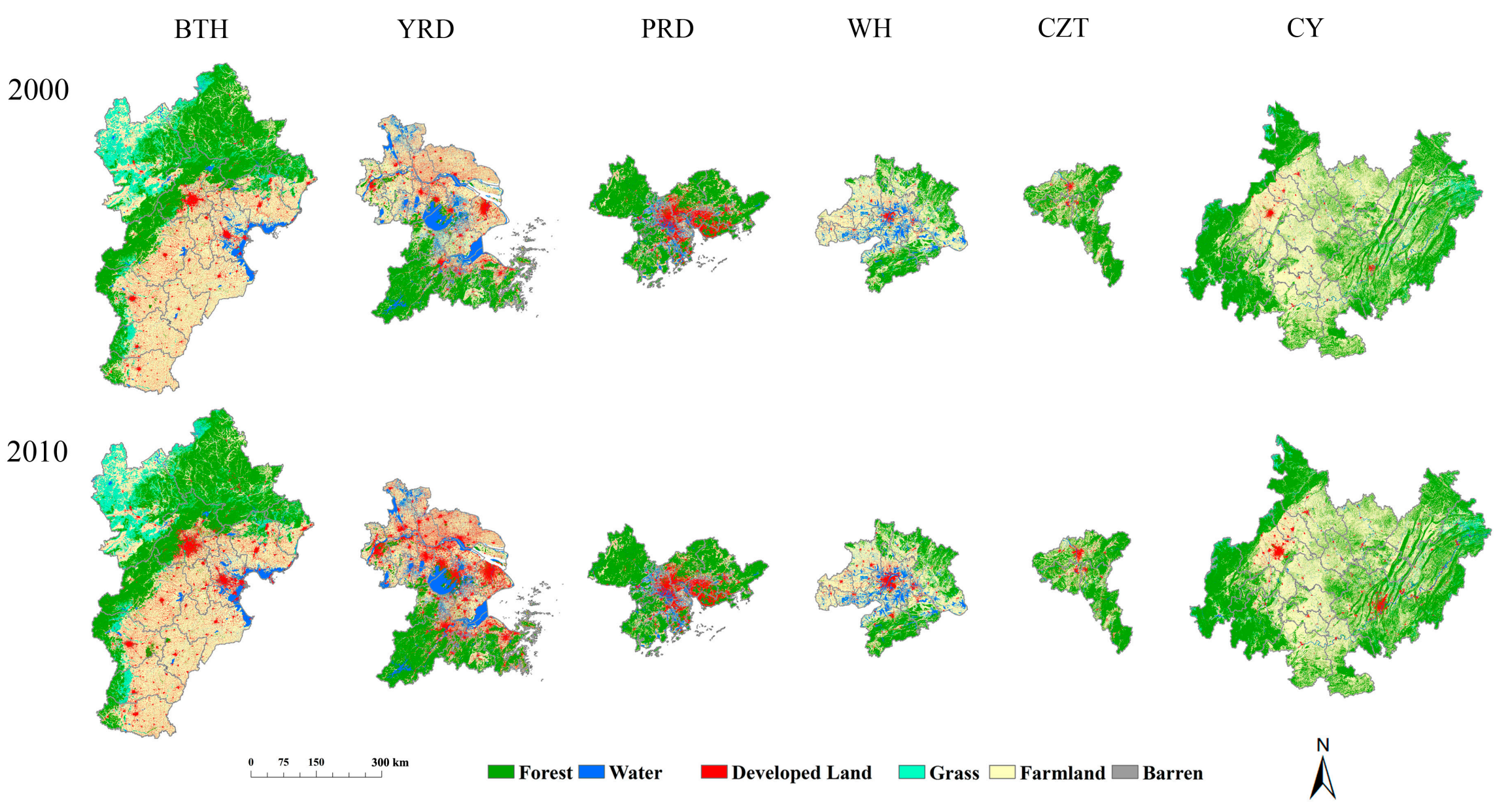

Figure 2. Land cover and land use of the six urban megaregions in 2000 and 2010. 
Table 1. Administrative boundary of the six urban megaregions.

\begin{tabular}{|c|c|c|}
\hline & Province & Prefecture City \\
\hline \multirow{3}{*}{ Beijing-Tianjin-Hebei } & Beijing & \\
\hline & Tianjin & \\
\hline & Hebei & $\begin{array}{l}\text { Tangshan, Baoding, Langfang, Qinhuangdao, Zhangjiakou, } \\
\text { Chengde, Cangzhou, Shijiazhuang, Xingtai, } \\
\text { Handan, Hengshui }\end{array}$ \\
\hline \multirow{3}{*}{ Yangtze River Delta } & Shanghai & \\
\hline & Jiangsu & $\begin{array}{l}\text { Nanjing, Suzhou, Wuxi, Changzhou, Zhenjiang, Nantong, } \\
\text { Yangzhou, Taizhou, }\end{array}$ \\
\hline & Zhejiang & Hangzhou, Ningbo, Huzhou, Jiaxing, Shaoxing, Zhoushan \\
\hline Pearl River Delta & Guangdong & $\begin{array}{l}\text { Guangzhou, Shenzhen, Foshan, Jiangmen, Dongguan, } \\
\text { Zhongshan, Zhaoqing, Huizhou }\end{array}$ \\
\hline Wuhan & Hubei & $\begin{array}{l}\text { Wuhan, Huangshi, Xianning, Huanggang, Xiaogan, Ezhou, } \\
\text { Xiantao, Tianmen }\end{array}$ \\
\hline Changsha-Zhuzhou-Xiangtan & Hunan & Changsha, Zhuzhou, Xiangtan \\
\hline \multirow[t]{2}{*}{ Chengdu-Chongqing } & Sichuan & $\begin{array}{l}\text { Chengdu, Deyang, Mianyang, Meishan, Ziyang, Suining, } \\
\text { Leshan, Ya'an, Zigong, Luzhou, Neijiang, Nanchong, Yibin, } \\
\text { Dazhou, Guangan }\end{array}$ \\
\hline & Chongqing & \\
\hline
\end{tabular}

\subsection{Classification Method}

We first generated the LULC map of 2010 by an object-based classification approach [20,21]. With this approach, the multi-resolution segmentation algorithm was used to create image objects. We created three levels of objects with the scale parameters setting as 10 (Level 1), 30 (Level 2), and 50 (Level 3) by testing different parameter values [20,21]. Objects at Level 1 were used for classification of water, grass, and barren land. Objects at Level 2 were used for identifying farmland and developed land, and those at Level 3 were used for forest land. Rulesets that used feature parameters such as NDVI, NDWI, brightness, size, shape, and adjacency were developed for the LULC classification. After automatic classification, extensive manual editing was conducted for classification refinement, using high spatial resolution data, such as $2.4 \mathrm{~m}$ QuickBird and $2.5 \mathrm{~m}$ SPOT imagery as reference data. Consequently, we obtained the 2010 map with overall accuracy greater than $96 \%$.

The 2010 map was then used as a reference map to generate the map in 2000 using an object-based backdating approach [20]. With this object-based backdating approach, we first performed change vector analysis to identify areas with change from 2000 to 2010, which were then classified by an object-based classification method. For the areas with no change, the LULC types in 2010 were backdated to the map of 2000. More details for this approach can be found in [20]. The overall accuracy of the maps in 2000 were also over $96 \%$.

\subsection{Measuring Urban Expansion and Forest Loss}

We used two indices to measure the magnitude and relative speed of urban expansion in the six megaregions, by following the method in [26,38-40]. The area of newly-developed land (Equation (1), $\left.A_{n e w}\right)$ was used to measure the magnitude of urban expansion. The relative speed of urban expansion was measured by the ratio between the area of newly-developed land and the area of previously existing developed land (Equation (2), $\mathrm{P}_{\text {new }}$ ), which was used to compare the urban expansion speed across megaregions with different sizes. $\mathrm{A}_{\text {new }}$ and $\mathrm{P}_{\text {new }}$ were calculated as follows:

$$
\mathrm{A}_{\text {new }}=\mathrm{A}_{\text {end }}-\mathrm{A}_{\text {start }}
$$




$$
\mathrm{P}_{\text {new }}=\frac{\mathrm{A}_{\text {new }}}{\mathrm{A}_{\text {start }}} \times 100 \%
$$

where $A_{\text {start }}$ represents the area of previously existing developed land, $A_{\text {end }}$ represents the area of developed land at the end time of expansion, and $A_{\text {new }}$ represents the net increase of the area of developed land.

We focused on forest loss caused by urban expansion. Consequently, we developed two indicators to identify conversions from forest to developed land. $A_{\mathrm{f} 2 \mathrm{~d}}$ represents the area of forests converted to newly-developed land from 2000 to 2010 . We used $\mathrm{P}_{\mathrm{f} 2 \mathrm{~d}}$ to measure the contribution of forests to newly-developed land, which was calculated by dividing the area of newly-developed land by the area of land from forest to developed land:

$$
\mathrm{P}_{\mathrm{f} 2 \mathrm{~d}}=\frac{\mathrm{A}_{\mathrm{f} 2 \mathrm{~d}}}{\mathrm{~A}_{\text {new }}^{\prime}} \times 100 \%
$$

where $\mathrm{A}_{\text {new }}^{\prime}$ represents the total gain of the area of developed land from forest, grass, water, farmland, and barren land.

\subsection{Landscape Metrics to Measure Forest Fragmentation and Developed Land Dispersion}

We selected three frequently-used class-level metrics to characterize the spatial pattern of developed land and forests in the six urban megaregions, both at the regional and city scales [41]. Landscape metrics at the city scale were used to quantify the relationships between the spatial pattern of urban expansion and forest loss and fragmentation. These metrics included the percent cover of landscape (PLAND) that measures the landscape composition, mean patch size (MPS), and patch density (PD) that quantify spatial patterns of developed land and forest fragmentation. The detailed descriptions and equations of these metrics are listed in Table 2.

Table 2. Description of the landscape metrics used in this study.

\begin{tabular}{llc}
\hline \multicolumn{1}{c}{ Metrics (Abbreviation) } & \multicolumn{1}{c}{ Description } & Equation \\
\hline $\begin{array}{l}\text { Percent cover of a specific } \\
\text { patch type (PLAND) }\end{array}$ & $\begin{array}{l}\text { Proportion of a specific patch type in the } \\
\text { landscape (unit: \%) }\end{array}$ & $\frac{100}{A} \times \sum_{i=1}^{n} a_{i}$ \\
\hline Mean patch size (MPS) & $\begin{array}{l}\text { Total patch area of a specific patch type } \\
\text { divided by patch number (unit: ha) }\end{array}$ & $\frac{1}{10,000 \times n} \times \sum_{i=1}^{n} a_{i}$ \\
\hline Patch density (PD) & $\begin{array}{l}\text { Number of patches for a specific patch } \\
\text { type divided by total landscape area } \\
\text { (unit: number per km }{ }^{2} \text { ) }\end{array}$ & $\frac{n}{A} \times 10^{6}$ \\
\hline
\end{tabular}

$a_{i}$, area of patch $i ; A$, landscape area; $n$, number of patches for a specific patch type.

\subsection{Statistical Analysis}

We first conducted the Pearson correlation analysis to examine the relationships between forest loss and fragmentation and spatial patterns of developed land for each urban megaregion, except for CZT, using the prefecture city as the unit of analysis. We excluded the CZT megaregion because there were only three cities in CZT, without enough samples for correlation analysis. We further conducted partial correlation analysis to investigate the relationships between percent cover of developed land and forest fragmentation, by controlling for the effect of the spatial pattern of developed land (i.e., using the PD of developed land as the controlled variable). Partial correlation analysis is necessary because spatial pattern metrics of developed land were highly correlated with its percent cover and, therefore, the Pearson correlation analysis may obtain spurious relationships between the percent cover of developed land and forest fragmentation. 


\section{Results}

\subsection{Urban Expansion in Six Megaregions}

From 2000 to 2010, the six urban megaregions experienced rapid urban expansion, but with great regional variations. The YRD urban megaregion had the most rapid urban expansion in terms of magnitude $\left(A_{\text {new }}\right)$, with an increase of $8944 \mathrm{~km}^{2}$ from a total area of developed land of 13,392 in 2000 to $22,335 \mathrm{~km}^{2}$ in 2010 (Table 3). The developed land increased by $3777 \mathrm{~km}^{2}$ for $\mathrm{BTH}, 2378 \mathrm{~km}^{2}$ for CY, $1806 \mathrm{~km}^{2}$ for PRD, $1450 \mathrm{~km}^{2}$ for $\mathrm{WH}$, and $388 \mathrm{~km}^{2}$ for CZT. However, the CY megaregion had the fastest relative speed ( $\mathrm{P}_{\text {new }}$ ) of urban expansion, with an increase of $83.3 \%$, followed by the YRD (66.8\%), WH (56.3\%), CZT (34.3\%), PRD (30.8\%), and BTH (21.1\%) (Table 3).

Table 3. The total area and proportional cover of developed land, and the area of newly-developed land and its ratio to the previously-existing developed land in six urban megaregions.

\begin{tabular}{ccccccc}
\hline \multicolumn{2}{c}{$\mathbf{2 0 0 0}$} & \multicolumn{2}{c}{$\mathbf{2 0 1 0}$} & \multicolumn{2}{c}{$\mathbf{2 0 0 0 - 2 0 1 0}$} \\
\hline & Area $\mathbf{( \mathbf { k m } ^ { 2 } )}$ & $\begin{array}{c}\text { Percentage } \\
\mathbf{( \% )}\end{array}$ & Area $\left.\mathbf{( k m}^{\mathbf{2}}\right)$ & $\begin{array}{c}\text { Percentage } \\
\mathbf{( \% )}\end{array}$ & $\mathbf{A}_{\text {new }}\left(\mathbf{k m}^{\mathbf{2}}\right)$ & $\begin{array}{c}\mathbf{P}_{\text {new }} \\
\mathbf{( \% )}\end{array}$ \\
\hline BTH & 17,858 & 8.3 & 21,635 & 10.0 & 3777 & 21.1 \\
YRD & 13,392 & 13.3 & 22,335 & 22.1 & 8944 & 66.8 \\
PRD & 5863 & 10.9 & 7669 & 14.2 & 1806 & 30.8 \\
WH & 2575 & 4.4 & 4024 & 6.9 & 1450 & 56.3 \\
CZT & 1129 & 4.0 & 1517 & 5.4 & 388 & 34.3 \\
CY & 2855 & 1.4 & 5233 & 2.5 & 2378 & 83.3 \\
\hline
\end{tabular}

\subsection{Forest Loss and Fragmentation in the Six Megaregions}

Percent cover of forest and its change varied greatly across regions. The CZT megaregion had the highest percent cover of forest, with 59.53\% in 2010, followed by the PRD (59.18\%), CY (46.46\%), BTH $(33.06 \%), \mathrm{WH}(26.40 \%)$, and YRD $(25.87 \%)$. The percent cover of forest increased slightly for the BTH $(0.50 \%)$, YRD $(0.74 \%)$, and CY (1.31\%) megaregions from 2000 to 2010. In contrast, the PRD, $\mathrm{WH}$, and CZT megaregions experienced net decreases in the amount of forest. For example, the PRD megaregion had a net loss of $246 \mathrm{~km}^{2}$, from a total area of forested land of 32,156 km² in 2000 to $31,910 \mathrm{~km}^{2}$ in 2010 (Table 4).

We focused on the forest loss caused by urban expansion and found that changes in forest were different from the net increase or decrease would suggest (Table 4). The area of forest loss caused by urban expansion, and its contribution to the newly-developed land varied greatly by megaregion. For example, the $\mathrm{CY}$ megaregion experienced the greatest loss of forests due to urban expansion, with an area of $467.34 \mathrm{~km}^{2}\left(0.51 \%\right.$ of the total area of forest), followed by the PRD megaregion $\left(407.87 \mathrm{~km}^{2}\right)$ (Table 4). In contrast, forests contributed to $34.05 \%$ of the newly developed land in the CZT megaregion, and $22.58 \%, 19.65 \%, 5.77 \%$ in PRD, CY and $\mathrm{WH}$, respectively. The ratio was smaller in YRD and BTH, with less than $3 \%$ of the newly-developed land converted from forests (Table 4 ).

Patch density of forests decreased in the megaregions of PRD, WH, CZT, and CY, but increased in BTH and YRD. Meanwhile, changes in mean patch size of forests were the opposite to that of the patch density (Table 5). For example, mean patch size of forests increased from 115.7 ha to 132.4 ha in the PRD megaregion, but decreased from 249.5 ha to 244.7 ha in the BTH megaregion (Table 5). 
Table 4. The total area and proportional cover of forested land, and the area of forest converted to newly developed land and its ratio to the total area of newly-developed land in six urban megaregions.

\begin{tabular}{ccccccccc}
\hline & \multicolumn{2}{c}{$\mathbf{2 0 0 0}$} & \multicolumn{2}{c}{$\mathbf{2 0 1 0}$} & \multicolumn{2}{c}{ Net Change } & \multicolumn{2}{c}{ Forest to Developed } \\
\hline & $\begin{array}{c}\text { Area } \\
\mathbf{( k m}^{\mathbf{2}} \mathbf{)}\end{array}$ & $\begin{array}{c}\text { Percentage } \\
\mathbf{( \% )}\end{array}$ & $\begin{array}{c}\text { Area } \\
\mathbf{( k m}^{\mathbf{2}} \mathbf{)}\end{array}$ & $\begin{array}{c}\text { Percentage } \\
\mathbf{( \% )}\end{array}$ & $\begin{array}{c}\text { Area } \\
\mathbf{( \mathbf { k m } ^ { \mathbf { 2 } } )}\end{array}$ & $\begin{array}{c}\text { Percentage } \\
\mathbf{( \% )}\end{array}$ & $\begin{array}{c}\mathbf{A}_{\mathbf{f} 2 \mathbf{d}} \\
\mathbf{( k m}^{\mathbf{2}} \mathbf{)}\end{array}$ & $\begin{array}{c}\mathbf{P}_{\mathbf{f 2 d}} \\
\mathbf{( \% )}\end{array}$ \\
\hline BTH & 70,314 & 32.56 & 71,607 & 33.06 & 1293 & 0.50 & 89.13 & 2.38 \\
YRD & 25,809 & 25.13 & 26,170 & 25.87 & 361 & 0.74 & 213.48 & 2.37 \\
PRD & 32,156 & 59.65 & 31,910 & 59.18 & -246 & -0.47 & 407.87 & 22.53 \\
WH & 15,352 & 26.50 & 15,278 & 26.40 & -74 & -0.10 & 83.70 & 5.76 \\
CZT & 16,912 & 60.20 & 16,724 & 59.53 & -188 & -0.67 & 132.89 & 34.05 \\
CY & 91,917 & 45.15 & 94,680 & 46.46 & 2763 & 1.31 & 467.34 & 19.63 \\
\hline
\end{tabular}

Table 5. Changes in patch density and mean patch size of forested land in the six urban megaregions.

\begin{tabular}{ccccc}
\hline & \multicolumn{2}{c}{$\mathbf{2 0 0 0}$} & \multicolumn{2}{c}{$\mathbf{2 0 1 0}$} \\
\hline & PD $\left(\mathbf{\mathbf { k m } ^ { 2 }}\right)$ & MPS (ha) & PD $\left(\mathbf{k m}^{\mathbf{2}}\right)$ & MPS (ha) \\
\hline BTH & 0.131 & 249.5 & 0.135 & 244.7 \\
YRD & 0.495 & 51.8 & 0.507 & 51.2 \\
PRD & 0.516 & 115.7 & 0.447 & 132.4 \\
WH & 0.527 & 50.3 & 0.516 & 51.1 \\
CZT & 0.702 & 87.2 & 0.684 & 88.6 \\
CY & 1.821 & 23.9 & 1.735 & 25.8 \\
\hline
\end{tabular}

\subsection{Quantifying the Relationships between Urban Expansion and Forest Loss and Fragmentation}

\subsubsection{Effects of Urban Expansion and Its Spatial Pattern on Forest Loss}

The percent cover of developed land had a significantly negative correlation with the percent cover of forests for all the megaregions in 2000 and 2010, except the WH and CY megaregions (Table 6), suggesting cities with higher percent cover of developed land tended to have lower percent cover of forested land.

The Pearson correlation analysis showed that patch density of developed land had a significantly negative correlation with percent cover of forested land for all megaregions, except the CY megaregion in 2000. However, the significance only remained for two megaregions-BTH and WH in 2010 (Table 6). In contrast, the mean patch size of developed land had a significantly negative correlation with percent cover of forested land only for YRD in 2010 (Table 6). The strength of the correlation between patch density of developed land and percent cover of forests varied across megaregions and by time. The correlation between patch density of developed land and percent cover of forests was stronger in BTH and WH than in the other megaregions.

Table 6. Pearson correlation between percent cover of forested land and metrics of developed land.

\begin{tabular}{ccccccc}
\hline \multicolumn{3}{c}{2000} & \multicolumn{3}{c}{2010} \\
\hline & PLAND & PD & MPS & PLAND & PD & MPS \\
\hline BTH $(n=13)$ & $-0.655^{*}$ & $-0.811^{* *}$ & -0.305 & $-0.557^{*}$ & $-0.792^{* *}$ & -0.271 \\
PRD $(n=9)$ & $-0.668^{*}$ & $-0.666^{*}$ & -0.411 & $-0.771^{*}$ & -0.279 & -0.471 \\
YRD $(n=15)$ & $-0.700^{* *}$ & $-0.796^{* *}$ & -0.081 & $-0.814^{* *}$ & -0.370 & $-0.522^{*}$ \\
WH $(n=9)$ & $-0.850^{* *}$ & $-0.829^{* *}$ & -0.609 & -0.662 & $-0.797^{*}$ & -0.240 \\
CY $(n=16)$ & -0.379 & -0.279 & -0.384 & -0.241 & -0.298 & -0.165 \\
\hline \multicolumn{7}{c}{ * Coefficient is significant at the 0.05 level; ${ }^{* *}$ Coefficient is significant at the 0.01 level. }
\end{tabular}




\subsubsection{Effects of Urban Expansion and Its Spatial Pattern on Forest Fragmentation}

The Pearson correlation analysis showed that percent cover of developed land had a significantly negative relationship with the mean patch size of forested land for the BTH and WH megaregions in 2000, for the PRD megaregion in 2010, and for the YRD megaregion in both years, suggesting cities with higher proportions of developed land had smaller forest patches (Table 7). Patch density of developed land had a significantly negative relationship with mean patch size of forested land for most of the megaregions in both years (Table 7). In contrast, mean patch size of developed land had no significant relationships with the mean patch size of forested land in any megaregion.

In contrast, the relationships between the percent cover of developed land and the patch density of forested land were less significant, and varied greatly by megaregion. Percent cover of developed land was only significantly correlated with the patch density of forested land for the PRD megaregion in both years, in a positive way. The percent cover of developed land was significantly correlated to the patch density of forested land for the YRD megaregion in 2010, and the WH megaregion in 2000, but in a negative way (Table 8 ).

Patch density of developed land was only significantly related to the patch density of forested land in the WH megaregion in both 2000 and 2010 (Table 8). Similarly, mean patch size of developed land was only significantly related to the patch density of forested land in the megaregions of YRD and PRD in 2010.

Table 7. Pearson correlation coefficients between mean patch size of forested land and metrics of developed land.

\begin{tabular}{ccccccc}
\hline & \multicolumn{5}{c}{$\mathbf{2 0 0 0}$} & \multicolumn{2}{c}{$\mathbf{2 0 1 0}$} \\
\hline & PLAND & PD & MPS & PLAND & PD & MPS \\
\hline BTH $(n=13)$ & $-0.617^{*}$ & $-0.705^{* *}$ & -0.406 & -0.551 & $-0.713^{* *}$ & -0.376 \\
PRD $(n=9)$ & -0.612 & $-0.751^{*}$ & -0.422 & $-0.673^{*}$ & -0.518 & -0.446 \\
YRD $(n=15)$ & $-0.622^{*}$ & $-0.706^{* *}$ & -0.04 & $-0.602^{*}$ & $-0.659^{* *}$ & -0.181 \\
WH $(n=9)$ & $-0.785^{*}$ & $-0.817^{* *}$ & -0.494 & -0.568 & $-0.810^{* *}$ & -0.098 \\
CY $(n=16)$ & -0.226 & -0.133 & -0.415 & -0.158 & -0.16 & -0.276 \\
\hline
\end{tabular}

* Coefficient is significant at the 0.05 level; ${ }^{* *}$ Coefficient is significant at the 0.01 level.

Table 8. Pearson correlation coefficients between patch density of forested land and metrics of developed land.

\begin{tabular}{|c|c|c|c|c|c|c|}
\hline & \multicolumn{3}{|c|}{2000} & \multicolumn{3}{|c|}{2010} \\
\hline & PLAND & PD & MPS & PLAND & PD & MPS \\
\hline $\mathrm{BTH}(n=13)$ & -0.320 & -0.418 & -0.060 & -0.292 & -0.324 & -0.126 \\
\hline $\operatorname{PRD}(n=9)$ & $0.848^{* *}$ & 0.557 & 0.657 & $0.896^{* *}$ & 0.137 & 0.700 * \\
\hline YRD $(n=15)$ & -0.447 & -0.467 & -0.174 & -0.571 * & 0.190 & -0.608 * \\
\hline $\mathrm{WH}(n=9)$ & $-0.751^{*}$ & -0.762 * & -0.498 & -0.544 & -0.741 * & -0.163 \\
\hline $\mathrm{CY}(n=16)$ & -0.234 & -0.308 & 0.375 & -0.276 & -0.275 & 0.082 \\
\hline
\end{tabular}

3.3.3. Effects of Urban Expansion on Forest Fragmentation after Controlling for the Effects of Its Spatial Pattern

We conducted partial correlation analysis to control for the effect of the spatial pattern of developed land to investigate the relationships between percent cover of developed land and forest fragmentation. We only selected the patch density of developed land as the controlling variable because the results of the Pearson correlation analysis showed that the patch density of developed land was highly correlated with forest fragmentation, but the relationships between the mean patch size of developed land and forest fragmentation were less significant (Tables 7 and 8 ). In addition, 
patch density and mean patch size were highly correlated. Therefore, we conducted partial correlation analysis by controlling for only the patch density of developed land.

Table 9 lists the partial correlation coefficients between percent cover of developed land and the two metrics of forest fragmentation. After controlling for the effect of the patch density of developed land, the correlations between the percent cover of developed land and forest fragmentation changed greatly (Tables 7-9). First, the percent cover of developed land was no longer significantly correlated to the mean patch size of forest for the BTH, YRD, and WH megaregions in 2000, but the negative correlations were still strong for the PRD and YRD megaregions in 2010 (Tables 7 and 9). Second, the percent cover of developed land was no longer significantly correlated to the patch density of forest for the WH megaregion (Tables 8 and 9). Third, the correlations between percent cover of developed land and the patch density of forest were stronger for the PRD and YRD megaregions, with a positive correlation for the PRD and, in contrast, a negative correlation for the YRD (Tables 8 and 9).

Table 9. Partial correlations between percent cover of developed land and metrics of forest fragmentation after controlling for the patch density of developed land.

\begin{tabular}{ccccc}
\hline & \multicolumn{2}{c}{2000} & \multicolumn{2}{c}{2010} \\
\hline & ForestMPS & ForestPD & ForestMPS & ForestPD \\
\hline BTH $(n=13)$ & -0.099 & 0.037 & -0.028 & -0.077 \\
PRD $(n=9)$ & -0.608 & $0.856^{* *}$ & $-0.872^{* *}$ & $0.930^{* *}$ \\
YRD $(n=15)$ & -0.159 & -0.148 & $-0.620^{*}$ & $-0.641^{*}$ \\
WH $(n=9)$ & -0.299 & -0.303 & -0.325 & -0.302 \\
CY $(n=16)$ & -0.343 & 0.220 & -0.044 & -0.085 \\
\hline
\end{tabular}

${ }^{*}$ Coefficient is significant at the 0.05 level; ${ }^{* *}$ Coefficient is significant at the 0.01 level.

\section{Discussion}

Our results indicated that urban expansion was a major driver of loss of forested land in all the six megaregions, particularly in the megaregions of $\mathrm{PRD}, \mathrm{CZT}$, and $\mathrm{CY}$, where forests are one of the dominant landscapes (Table 4). This result is consistent with those from previous studies conducted for single cities, or at the urban region scales $[18,42,43]$. The total area of loss in forested land caused by urban expansion, however, varied greatly by megaregions. The total areas of loss in forested land in the PRD and CY megaregions were nearly five times that in the BTH and WH megaregions, and twice that in the YRD megaregions. These differences were largely due to the different dominant land cover types in the megaregions. The PRD and CY megaregions were dominated by forests, with forest coverage of approximately $60 \%$ and $45 \%$, respectively (Figure 2, Table 4). Consequently, much of the newly-developed land occurred in previously-forested land.

The loss of forests have significant social and ecological implications, but which may differ from megaregions, as the dominant types of forests varied greatly in the six megaregions and, consequently, the major types of forest lost varied by megaregions, as well as their social and ecological functions [4446]. In the PRD megaregion, loss of forests were dominated by evergreen broadleaf and planted forests, but were evergreen and deciduous broadleaf in the $\mathrm{CY}$ megaregion. The major types of forest lost were evergreen coniferous forest in the CZT and WH megaregions, evergreen and deciduous bushes in the YRD megaregion, and deciduous bushes in the BTH megaregion.

The correlation analysis at the prefecture city level indicated that the mean patch size of forested land decreased with the increase of proportional cover of developed land, suggesting that urban expansion resulted in forest fragmentation. This result is consistent with previous studies that found urban expansion led to forest fragmentation $[18,29,30]$. However, at the megaregion scale, the increase in mean patch size of forested land indicated the decrease in the level of forest fragmentation in most megaregions (Table 5). These changes were likely due to the Grain for Green Program (GGP), aiming to increase the forest cover in former cropland located at steep slopes [47,48]. For example, the CY 
megaregion had the most rapid expansion of developed land, with an increase of $83.3 \%$ from 2000 to 2010 (Table 3). At the same time the percent cover of forest did not decrease, but increased by $1.31 \%$ (Table 4). Forests generated by the GGP to some extent offset the loss of forests caused by urban expansion, particularly in the western mountainous area [47-49].

Our results also indicated that spatial pattern of developed land, as measured by patch density in this study, could play a significant role in forest fragmentation (Table 7). The impacts of the spatial pattern of developed land on forest fragmentation, and its relative importance to the percent cover of developed land, however, varied by megaregions. For example, after controlling for the patch density of developed land, the negative relationship between proportional cover of developed land with the mean patch size of forested land became stronger in both the PRD and YRD megaregions, suggesting that the percentage of developed land in cities of the PRD and YRD was the major factor for forest fragmentation. In contrast, the correlations between the proportional cover of developed land and the mean patch size of forested land was no longer significant in the BTH and WH megaregions after controlling for the patch density of developed land, indicating that the impact of spatial pattern of developed land is more important in the BTH and WH megaregions. The different roles of patch density on forest fragmentation might be related to the differentiated morphological types of urban expansion in different megaregions [40,42,50,51], as dispersed urban expansion can lead to increased forest fragmentation [42,50]. For example, the PRD was dominated by expansion of infilling, the YRD was dominated by infilling and edge-expansion, and the BTH had the highest proportion of edge-expansion from 2000 to 2010 [40]. It would be interesting to examine the effects of different types of morphologies of urban expansion (e.g., leapfrogging, edge-expansion, and the infilling) on forest fragmentation in future studies. In addition, we quantified forest fragmentation only by mean patch size and patch density. Future studies that use more comprehensive measures of fragmentation, or focus on the changes at the patch level, would be highly desirable.

\section{Conclusions}

Previous studies revealed that increasing the proportional cover of developed land led to considerable loss and fragmentation of forested land. However, few studies have examined how the spatial pattern of developed land affects forest loss and fragmentation. Here, we conducted a comparison study in six rapidly urbanizing megaregions in China to investigate the effects of urban expansion and its spatial pattern on forest loss and fragmentation from 2000-2010. We found that (1) urban expansion was a major driver of forest land loss in the CZT, PRD, and CY megaregions, with $34.05 \%, 22.58 \%$, and $19.65 \%$ of newly-developed land converted from forests, but not in the WH, YRD, and BTH megaregions. (2) Both the proportional cover and spatial pattern of developed land significantly affected forest fragmentation, but their relative importance varied by megaregions. (3) Proportional cover of developed land was the major factor for forest fragmentation at the city level for the PRD and YRD megaregions, but the impact of the spatial pattern of developed land was more important for the BTH and WH megaregions. Results from studies provide insights on better understanding urban expansion and its spatial pattern on forest loss and fragmentation.

Acknowledgments: This research was funded by the National Natural Science Foundation of China (grant no. 41590841, grant no. 41422014), the project "Developing key technologies for establishing ecological security patterns at the Beijing-Tianjin-Hebei urban megaregion" of the National key research and development program (2016YFC0503004), the Key Research Program of Frontier Sciences, CAS (QYZDB-SSW-DQC034), and the China Ecosystem Survey (2000-2010) (grant no. STSN-12-00).

Author Contributions: Weiqi Zhou designed this research. Weiqi Zhou, Sai Zhang, Wenjuan Yu, Jing Wang, and Weimin Wang analyzed the data and wrote the paper.

Conflicts of Interest: The authors declare no conflict of interest. 


\section{References}

1. Drummond, M.A.; Loveland, T.R. Land-use pressure and a transition to forest-cover loss in the Eastern United States. Bioscience 2010, 60, 286-298. [CrossRef]

2. Foley, J.A.; DeFries, R.; Asner, G.P.; Barford, C.; Bonan, G.; Carpenter, S.R.; Chapin, F.S.; Coe, M.T.; Daily, G.C.; Gibbs, H.K.; et al. Global consequences of land use. Science 2005, 309, 570-574. [CrossRef] [PubMed]

3. Zhou, W.; Pickett, S.T.A.; Cadenasso, M.L. Shifting concepts of urban spatial heterogeneity and their implications for sustainability. Landsc. Ecol. 2016, 32, 15-30. [CrossRef]

4. Turner, B.L.; Lambin, E.F.; Reenberg, A. The emergence of land change science for global environmental change and sustainability. Proc. Natl. Acad. Sci. USA 2007, 104, 20666-20671. [CrossRef] [PubMed]

5. Du, N.R.; Ottens, H.; Sliuzas, R. Spatial impact of urban expansion on surface water bodies-A case study of Wuhan, China. Landsc. Urban Plan. 2010, 94, 175-185. [CrossRef]

6. Matteucci, S.D.; Morello, J. Environmental consequences of exurban expansion in an agricultural area: The case of the argentinian pampas ecoregion. Urban Ecosyst. 2009, 12, 287-310. [CrossRef]

7. Su, S.; Xiao, R.; Jiang, Z.; Zhang, Y. Characterizing landscape pattern and ecosystem service value changes for urbanization impacts at an eco-regional scale. Appl. Geogr. 2012, 34, 295-305. [CrossRef]

8. Van Delden, L.; Rowlings, D.; Scheer, C.; Grace, P.R. Urbanisation-related land use change from forest and pasture into turf grass modifies soil nitrogen cycling and increases $\mathrm{N}_{2} \mathrm{O}$ emissions. Biogeosciences 2016, 13, 6095-6106. [CrossRef]

9. Zhou, W.; Wang, J.; Cadenasso, M.L. Effects of the spatial configuration of trees on urban heat mitigation: A comparative study. Remote Sens. Environ. 2017, 195, 1-12. [CrossRef]

10. Gong, C.; Chen, J.; Yu, S. Spatiotemporal dynamics of urban forest conversion through model urbanization in shenzhen, china. Int. J. Remote Sens. 2011, 32, 9071-9092. [CrossRef]

11. Kupfer, J.A. National assessments of forest fragmentation in the us. Glob. Environ. Chang. 2006, 16, 73-82. [CrossRef]

12. MacDonald, K.; Rudel, T.K. Sprawl and forest cover: What is the relationship? Appl. Geogr. 2005, 25, 67-79. [CrossRef]

13. Seto, K.C.; Guneralp, B.; Hutyra, L.R. Global forecasts of urban expansion to 2030 and direct impacts on biodiversity and carbon pools. Proc. Natl. Acad. Sci. USA 2012, 109, 16083-16088. [CrossRef] [PubMed]

14. Fujita, A.; Maeto, K.; Kagawa, Y.; Ito, N. Effects of forest fragmentation on species richness and composition of ground beetles (Coleoptera: Carabidae and Brachinidae) in urban landscapes. Entomol. Sci. 2008, 11, $39-48$. [CrossRef]

15. McKinney, M.L. Effects of urbanization on species richness: A review of plants and animals. Urban Ecosyst. 2008, 11, 161-176. [CrossRef]

16. Ng, C.N.; Xie, Y.J.; Yu, X.J. Measuring the spatio-temporal variation of habitat isolation due to rapid urbanization: A case study of the shenzhen river cross-boundary catchment, China. Landsc. Urban Plan. 2011, 103, 44-54. [CrossRef]

17. Tao, H.; Nan, Y.; Liu, Z.-F. Spatiotemporal patterns of forest in the transnational area of changbai mountain from 1977 to 2015: A comparative analysis of the chinese and dprk sub-regions. Sustainability 2017, 9, 1054. [CrossRef]

18. Zhou, W.; Huang, G.; Pickett, S.T.A.; Cadenasso, M.L. 90 years of forest cover change in an urbanizing watershed: Spatial and temporal dynamics. Landsc. Ecol. 2011, 26, 645-659. [CrossRef]

19. Peng, J.; Liu, Y.; Shen, H.; Han, Y.; Pan, Y. Vegetation coverage change and associated driving forces in mountain areas of northwestern Yunnan, China using rs and gis. Environ. Monit. Assess. 2012, 184, 4787-4798. [CrossRef] [PubMed]

20. Yu, W.; Zhou, W.; Qian, Y.; Yan, J. A new approach for land cover classification and change analysis: Integrating backdating and an object-based method. Remote Sens. Environ. 2016, 177, 37-47. [CrossRef]

21. Zhou, W.; Troy, A.; Grove, M. Object-based land cover classification and change analysis in the baltimore metropolitan area using multitemporal high resolution remote sensing data. Sensors 2008, 8, 1613-1636. [CrossRef] [PubMed]

22. Liu, H.; Weng, Q. Landscape metrics for analysing urbanization-induced land use and land cover changes. Geocarto Int. 2013, 28, 582-593. [CrossRef] 
23. Jeon, S.B.; Olofsson, P.; Woodcock, C.E. Land use change in new england: A reversal of the forest transition. J. Land Use Sci. 2013, 9, 105-130. [CrossRef]

24. Kennedy, R.E.; Yang, Z.; Braaten, J.; Copass, C.; Antonova, N.; Jordan, C.; Nelson, P. Attribution of disturbance change agent from landsat time-series in support of habitat monitoring in the puget sound region, USA. Remote Sens. Environ. 2015, 166, 271-285. [CrossRef]

25. Xian, G.; Crane, M. Assessments of urban growth in the tampa bay watershed using remote sensing data. Remote Sens. Environ. 2005, 97, 203-215. [CrossRef]

26. Haas, J.; Furberg, D.; Ban, Y. Satellite monitoring of urbanization and environmental impacts—A comparison of Stockholm and Shanghai. Int. J. Appl. Earth Obs. Geoinf. 2015, 38, 138-149. [CrossRef]

27. Li, J.; Li, C.; Zhu, F.; Song, C.; Wu, J. Spatiotemporal pattern of urbanization in shanghai, China between 1989 and 2005. Landsc. Ecol. 2013, 28, 1545-1565. [CrossRef]

28. Salvati, L.; Biasi, R.; Carlucci, M.; Ferrara, A. Forest transition and urban growth: Exploring latent dynamics (1936-2006) in Rome, Italy, using a geographically weighted regression and implications for coastal forest conservation. Rend. Lincei 2015, 26, 577-585. [CrossRef]

29. Cao, H.; Liu, J.; Fu, C.; Zhang, W.; Wang, G.; Yang, G.; Luo, L. Urban expansion and its impact on the land use pattern in xishuangbanna since the reform and opening up of China. Remote Sens. 2017, 9, 137. [CrossRef]

30. Nielsen, A.B.; Hedblom, M.; Olafsson, A.S.; Wiström, B. Spatial configurations of urban forest in different landscape and socio-political contexts: Identifying patterns for green infrastructure planning. Urban Ecosyst. 2016, 20, 379-392. [CrossRef]

31. National Bureau of Statistics of China. China Statistical Yearbook 2016; China Statistics Press: Beijing, China, 2016.

32. Jiangsu Provincial Bureau of Statistics. Jiangsu Statistical Yearbook 2016; China Statistics Press: Beijing, China, 2016.

33. Zhejiang Provincial Bureau of Statistics. Zhejiang Statistical Yearbook 2016; China Statistics Press: Beijing, China, 2016.

34. Guangdong Provincial Bureau of Statistics. Guangdong Statistical Yearbook 2016; China Statistics Press: Beijing, China, 2016.

35. Hubei Provincial Bureau of Statistics. Hubei Statistical Yearbook 2011; China Statistics Press: Beijing, China, 2011.

36. Sichuan Provincial Bureau of Statistics. Sichuan Statistical Yearbook 2015; China Statistical Press: Beijing, China, 2015.

37. Chongqing Provincial Bureau of Statistics. Chongqing Statistical Yearbook 2015; Statistical Press of China: Beijing, China, 2015.

38. Haas, J.; Ban, Y. Urban growth and environmental impacts in Jing-jin-Ji, the Yangtze, River Delta and the Pearl River Delta. Int. J. Appl. Earth Obs. Geoinf. 2014, 30, 42-55. [CrossRef]

39. Hu, Y.; Ban, Y.; Zhang, Q.; Liu, J. The trajectory of urbanization process in the Yangtze River Delta during 1990 to 2005. In Proceedings of the 2009 Joint conference on Urban Remote Sensing Event, Shanghai, China, 20-22 May 2009; pp. 1-8.

40. Yu, W.; Zhou, W. The spatiotemporal pattern of urban expansion in China: A comparison study of three urban megaregions. Remote Sens. 2017, 9, 45. [CrossRef]

41. Mcgarigal, K.S.; Cushman, S.A.; Neel, M.C.; Ene, E. Fragstats: Spatial Pattern Analysis Program for Categorical Maps; Version 4; University of Massachusetts: Amherst, MA, USA, 2002.

42. Radeloff, V.C.; Hammer, R.B.; Stewart, S.I. Rural and suburban sprawl in the U.S. Midwest from 1940 to 2000 and its relation to forest fragmentation. Conserv. Biol. 2005, 19, 793-805. [CrossRef]

43. Teixeira, A.M.G.; Soares-Filho, B.S.; Freitas, S.R.; Metzger, J.P. Modeling landscape dynamics in an atlantic rainforest region: Implications for conservation. For. Ecol. Manag. 2009, 257, 1219-1230. [CrossRef]

44. Baldocchi, D.; Vogel, C. Energy and $\mathrm{CO}_{2}$ flux densities above and below a temperate broad-leaf forest and a boreal pine forest. Tree Physiol. 1996, 16, 5-16. [CrossRef] [PubMed]

45. Sohngen, B.; Brown, S. The influence of conversion of forest types on carbon sequestration and other ecosystem services in the south central United States. Ecol. Econ. 2006, 57, 698-708. [CrossRef]

46. Zhang, X.; Wang, M.; Liang, X. Quantitative classification and carbon density of the forest vegetation in lüliang mountains of china. Plant Ecol. 2009, 201, 1-9. [CrossRef] 
47. Lindquist, E.J.; D'Annunzio, R.; Gerrand, A.; Macdicken, K.; Achard, F.; Beuchle, R.; Brink, A.; Eva, H.D.; Mayaux, P.; Sanmiguelayanz, J. Global Forest Land-Use Change 1990-2005; Fao Forestry Paper No. 169; Food and Agriculture Organization of the United Nations (FAO) and European Commission Joint Research Center (JRC): Rome, Italy, 2012.

48. Zhou, P.; Wen, A.B.; Yan, D.C.; Shi, Z.L.; Guo, J.; Zhan-Sheng, J.U.; Zhang, Y.L. Changes in land use and agricultural production structure before and after the implementation of grain for green program in western China-taking two typical counties as examples. J. Mt. Sci. 2014, 11, 526-534. [CrossRef]

49. Cao, S.; Chen, L.; Yu, X. Impact of China's grain for green project on the landscape of vulnerable arid and semi-arid agricultural regions: A case study in northern shaanxi province. J. Appl. Ecol. 2009, 46, 536-543. [CrossRef]

50. Gong, C.; Yu, S.; Joesting, H.; Chen, J. Determining socioeconomic drivers of urban forest fragmentation with historical remote sensing images. Landsc. Urban Plan. 2013, 117, 57-65. [CrossRef]

51. Zhao, S.; Zhou, D.; Zhu, C.; Qu, W.; Zhao, J.; Sun, Y.; Huang, D.; Wu, W.; Liu, S. Rates and patterns of urban expansion in China's 32 major cities over the past three decades. Landsc. Ecol. 2015, 30, 1541-1559. [CrossRef]

(C) 2017 by the authors. Licensee MDPI, Basel, Switzerland. This article is an open access article distributed under the terms and conditions of the Creative Commons Attribution (CC BY) license (http://creativecommons.org/licenses/by/4.0/). 